\title{
INTEGRATING MASTER PLANNING FOR URBAN DEVELOPMENT ON THE INTELLIGENT TRANSPORT SYSTEM IN VIETNAM \\ Hoang Phuong Nguyen
}

Academy of Politics Region II, Vietnam.

Email: nghoangphuong11@gmail.com

\author{
Article History: Received on $08^{\text {th }}$ September 2019, Revised on $22^{\text {nd }}$ February 2020, Published on $28^{\text {th }}$ February 2020
}

\section{Abstract}

Purpose of the study: Intelligent Transport System (ITS) is being developed, researched, and built to solve traffic congestion in recent years. Many studies and seminars were organized but the results were still limited and fragmented. To build a smart city with intelligent transport system always starts from the planning work.

Methodology: Methods of aggregating and statistical data from the Ministry of Transport to ITS and the overall planning of urban transport; Review and propose optimal solutions for integrated urban planning of ITS.

Main Findings: The role of urban transportation and the current status of ITS development planning in urban planning in Vietnam. On that basis, it is necessary to integrate existing master plans into an urban development master plan that covers socio-economic development planning, land use, and urban construction. It is based on the planning of smart and modern urban transport development.

Applications of this study: The paper proposes content to integrate ITS planning in urban planning in 4 steps to ensure sustainability and updates.

Novelty/Originality of this study: The paper presents an overview of ITS system and ITS planning and its relation to urban planning in which, in addition to the traditional planning content, some new contents of ITS planning need to be integrated to meet for building and managing the city in a new age. This study is to affirm the need for integrating urban development master plans based on intelligent transportation system planning.

Keywords: Intelligent Transport System, Urban Development, Integrating Master Planning.

\section{INTRODUCTION}

Application of advanced technology to support vehicle flow management has been popular for over 70 years with early efforts to control traffic signals at intersections and railroad crossings in the US and Europe. Vehicle manufacturers have developed advanced technologies to create safer, more comfortable vehicles, reducing driving pressure. A lot of similar technology can be found on buses and trains (Makino, Tamada, Sakai, \& Kamijo, 2018). Advanced technologies are increasingly being applied to the management of large public transport networks, and in updating bus and train destination information for passengers. In the field of freight transport, a range of technologies have been applied to make transportation easier and facilitate commercial transactions but are part of the supply chain. In general, these technologies are now known as "intelligent transport systems" (ITS). When applied carefully, ITS can create safer, more secure, more convenient transportation systems, and reduce environmental impact (Xiong et al., 2015).

ITS can be defined as the application of computing, information and communications technology to the management of vehicles and networks related to the movement of people and goods in real-time; help organize traffic safer and more convenient and limit accidents and incidents when participating in traffic (Nguyen, 2019). ITS main functions are to manage, operate, supervise and provide transportation services; Ensure smooth, convenient and safe transportation (Buszynski \& Roberts, 2014). Thus, the planning of intelligent traffic systems should be saved to the Traffic Management Center as the main to connect multimedia traffic; traffic monitoring system, electronic tolls, signal lights, traffic control ... Through the center, with the intelligent management system, it provides the participants in the traffic with the timeliest and accurate information to choose the itinerary, means of participation (Chen, Tabssum, \& Nguyen, 2019).

According to the International Organization for Standardization (ISO), the ITS service provides users with 11 groups and 44 basic services. Users include individuals, owners of convoys, business owners, owners of transport infrastructure systems ... These services are coordinated and provided consistently by the traffic management center. In the process of researching, developing and developing ITS, urbanists have synthesized ITS priority services by urban scale (Raval \& Gupta, 2015). This is one of the basic standards to apply the construction of the ITS system for smart cities (Muhammad, Kumar, Cianca, \& Lindgren, 2018). Applying advanced technology to support media management has become popular for more than half a century. Since the 1960 s, the United States has begun researching the first intelligent traffic system with the control of traffic signal systems. Not long after that, a number of European and Asian countries (especially Japan) also began to study this field ( $\underline{\text { Yu \& Zhao, 2019)}) . ~}$

Experiencing the history of formation and development of ITS, to successfully deploy ITS in urban transport in particular and national transportation in general. Pioneers have established unified ITS organizations with roles, research functions, development planning and application of the ITS system (Li, Qu, Zhang, Wang, \& Ran, 2019). ITS development plans are integrated into each country's urban development strategy planning framework, from which to propose specific activities, 
suitable for each stage of socio-economic development and science and technology. To achieve the achievements of ITS development today; countries have studied the system of ITS standards and criteria as an important legal basis for the synchronous and unified construction of the national ITS system (Wang, Lu, Xi, \& Nguyen, 2019). In addition, ITS master plans are always inherited and integrated into national and urban overall strategic plans (Tokody, Mezei, \& Schuster, 2017). Which technology application, application or development always requires compliance with standards, regulations as well as planning approved by competent authorities (Xu, Zhai, \& Nguyen, 2019).

However, in Vietnam, the two most common phenomena in urban planning today are the situation which is often referred to as the "suspended planning" and the "planning superposition". This situation has really become a pressing issue and is one of the basic causes of inadequacies in land management, basic construction, causing annoyances in social life (Phuong, 2019). So far, there have been many different information and assessments about the causes of the above phenomena. However, most publications are often of a mass media and conclusions often stop at describing the phenomenon. The question of the cause of "suspended planning" is still ahead, requiring scientific and objective research (V. T. Pham, 2019). The main question of this research is: is having too many different types of planning but overall size one of the basic causes of the suspended planning phenomenon?

In this paper, in order to answer the above research questions, the author chooses the method of conducting research to analyze current documents and legal documents according to the following steps: (1) Identify the role of the Transport system in particular and ITS in particular in urban planning; (2) Analyze the situation of IST in the urban development master planning system in Vietnam; (3) Establish and propose to build an integrated urban development plan based on intelligent transportation planning.

\section{ROLE OF INTELLIGENT TRANSPORT SYSTEM IN URBAN DEVELOPMENT}

According to (T. Zhang, Zhou, Meng, \& Li, 2019), urban activities and transportation systems are mutually related, binding and decisive in the process of formation, development, and operation. The transport infrastructure network and the availability of vehicles and transport services determine site selection for all urban land uses. Besides, in the practice of making and implementing urban development planning, the transport infrastructure network is the basis for formulating and functional urban areas (Chen et al., 2019). Moreover, it is a space to deploy planning and conduct construction and installation of other urban technical infrastructure systems. Finally, it is also the basis for locating urban social infrastructure works (Schlingensiepen, Nemtanu, Mehmood, \& McCluskey, 2016). This confirms the role of the urban spatial structure of the transport infrastructure network and affirms the supply of vehicles and transport services play a critical role in determining the level of activities that take place at different locations in urban space. Figure 1 shows the logical architecture of the intelligent transport system, where the relationships of activities, functions, processes and information data, etc. are closely linked and organic (Lom, Pribyl, \& Svitek, 2016).

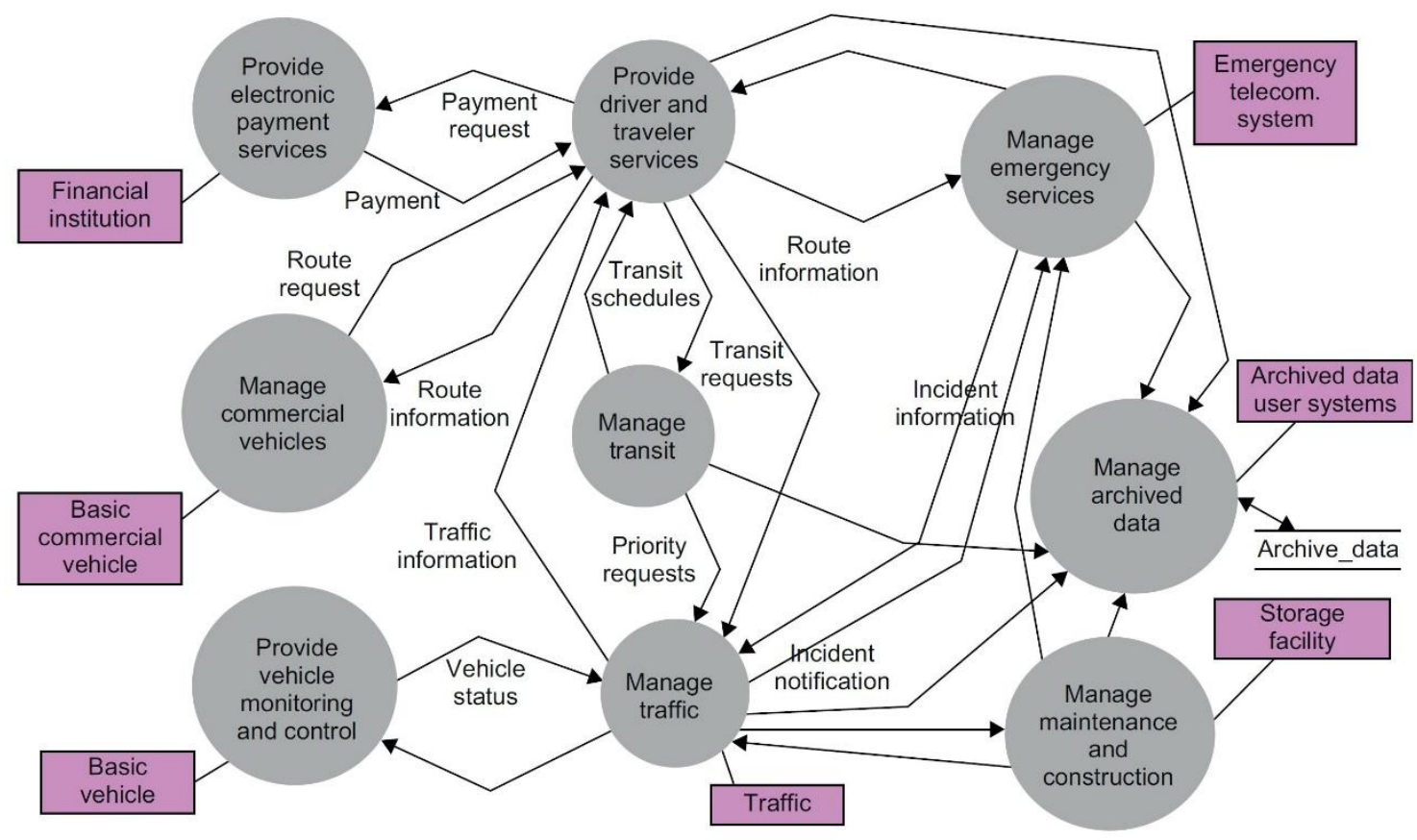

Figure 1: Data flow of logical architecture in ITS (T. Zhang et al., 2019)

In contrast, the choice of location of urban activities places requirements on the availability of vehicles and transport services. The schedule of activities at different locations in the city determines the time and space characteristics of traffic demands. The character of urban activity determines the direction, route, and velocity of urban traffic (Walker et al., 2019). The reciprocal, binding and mutually determined relationship between urban and transport is the main scientific and 
practical basis, which requires that at all times the synchronous integration between urban development must always be ensured and transport in all stages of policymaking, planning, financing planning, planning implementation and impact control of development projects.

Cities also have important roles such as government, economy, commerce, or cultural and educational centers. The development of nations and its key cities faces many problems. Many developing countries have experienced periods of strong economic growth which significantly increased people's income levels. Combined with that development, industrialization has witnessed rapid growth (L. Zhang, Li, \& Phuong, 2019). Developing countries are having a very diverse experience in industrialization. In most developing urban cities, traffic congestion has been around for more than two decades, but now the problem is spreading to other areas and takes several hours a day. Many of the local cities, with increasing numbers, are also experiencing this situation (Hoang, Le, Pham, \& Tham, 2019).

ITS plays a very important role in providing scheduling information and transportation services in many forms. This information helps passengers of all ages and even people with disabilities so they can better plan their trip. The information about the transportation routes of buses, trains or trains provided by ITS contributes to the great benefits for passengers during their journey (Hoang \& Pham, 2019). ITS encourages people to use public transport while increasing walking and cycling by making it convenient for passengers to travel in and out of the stops or the station of public transport. An integral part of the traffic regulation and control system of any city is the use of ITS to protect pedestrians and bicyclists and giving them priority traffic on perfect routes as well as "green" areas (Mihankhah, Delnavaz, \& Khaligh, 2016).

Surveillance, coordination and communication technologies often conducted in real-time can provide safety assistance in security and emergency situations. By improving the performance of a more efficient and efficient transportation system, the ITS system has brought many benefits to individuals involved in transportation as well as the whole society. The management of the transportation system can be enhanced through the use of ITS, for example, an advanced traffic management system, which ensures faster travel frequency for public transportation, providing access priority for pedestrians and bicyclists, and in areas suitable for cars (Hoang \& Pham, 2018). Commercial drivers also benefit from the aforementioned utilities that help them improve their productivity and reduce per diem. Modern ITS systems can be used to improve the efficiency of areas with limited road traffic by creating an advanced traffic management mechanism capable of automatic traffic segmentation and safe to meet the moving needs of buses in the peak directions (Razmjoo \& Davarpanah, 2019).

\section{PROPOSING THE APPLICATION OF 4.0 TECHNOLOGY IN DEVELOPING TRAFFIC TRANSPORTATION}

\section{Current situation of transport planning in urban planning}

Currently, urban transport planning is integrated into urban planning schemes or made separately for urban centers directly under the Central Government. The contents and requirements for the planning of development of the transport system are specified in the planning law and related standards and standards (QCVN 01: 2008; TCVN 104: 2007 ...). However, there are no specific regulations on ITS development in transport planning (Massard, Leuenberger, \& Dong, 2018). Therefore, there has not been an urban master plan in which ITS development orientation in the development of an asynchronous and sustainable transportation system. As a result, ITS construction and application in Vietnam's urban system is still fragmented and not really effective (Smajgl et al., 2015).

ITS research has been carried out in recent years and achieved certain achievements, making an important contribution to the practical implementation process. Research institutes, universities, and technology companies all have researched on this issue (Jahn, Kersten, \& Ringle, 2018). In 1999, the Transport Science and Technology Institute implemented a ministry-level research project: "Researching and applying intellectual transport system" with the aim of studying ITS system in the world and applicability in Vietnam, proposing initial applications; in 2009, the Institute continued to implement the project "Researching and applying ITS in exploitation management, traffic management and toll collection on Vietnam motorway system". In the key state-level Science and Technology Program for the period of 2011-2015, a number of state-level projects related to ITS have been implemented such as: "Building ITS structure and information technology standards," communication, control applied in ITS in Vietnam "(2012-2013) (Jiang \& Wang, 2018); and the topic "Research, design, and manufacture of equipment and facilities, and systems of automatic inspection, supervision and administration for road traffic safety". In addition, some other studies can be mentioned such as "Applied research and development of automation technology" conducted by Hanoi University of Transport in 2007-2010; and the topic "Requirements for service quality in the Internet using ITS" of the Post and Telecommunications Academy and the Post and Telecommunications Institute of Science and Technology. These are fundamental and initial studies in the field of ITS in Vietnam. In addition, JICA (Japan) studies on the ITS field have made important contributions to the process of ITS research and application in Vietnam. The JICA studies focused on the real situation and needs of ITS application of Vietnam, through 3 research stages: Surveying the needs, proposing the implementation roadmap and the overall planning; Support ITS implementation and ITS integrated research in national highways of Northern Vietnam. This includes assistance in developing standards and standards in the field of ITS. However, there is a lack of an integrated urban development master plan with integrated ITS in urban transport planning, so far ITS development projects and applications have not achieved the expected results (Choi \& Mai, 2018). 


\section{Current situation of ITS development planning in urban areas}

In Vietnam, ITS has started to be implemented in recent years and has achieved very positive initial results. By the end of 2018, according to statistics of the Ministry of Transport, our country's road system has a total length of 570,448 km, of which the national highway is $24,136 \mathrm{~km}$, expressway is $816 \mathrm{~km}$, provincial road is $25,741 \mathrm{~km}$, district road is $58,347 \mathrm{~km}$, urban road is $26,953 \mathrm{~km}$, commune road is $144,670 \mathrm{~km}$, hamlet is $181,188 \mathrm{~km}$ and inner road is $108,597 \mathrm{~km}$. Traffic on the roads is mixed traffic, with a high proportion of individual motor vehicles (According to statistics, by the middle of 2018 the total number of motor vehicles in circulation is 3,769,126 vehicles, the number of motorbikes in circulation is 55,138,589 vehicles) (Nguyen, 2019). The great media growth of road users also has certain limitations. Many problems that need to be solved include: the rate of traffic accidents is still high, traffic jams are still common in urban areas, environmental pollution is getting more and more serious, management system is limited, service quality and performance are low, not meeting the development needs of society (Nisar \& Prabhakar, 2017).

Investment in developing the transport infrastructure system is one of the top priorities that the Ministry of Transport is carrying out. According to the planning of Vietnam's road transport system, upgrading, building and developing the national highway system are of interest and priority for implementation. In the process, the ITS application is also focused and promptly conducted in order to build a safe and sustainable transportation system. Decision 355 / QD-TTg of the Prime Minister approving the Transport Development Strategy to 2020 and a vision to 2030, in which identifying transport is an important part, one of 3 breakthrough stages that need investment priority; develop synchronous, focused transport infrastructure, implementation stages in accordance with modern orientation; promote the socialization of transport infrastructure development investment; attaching importance to the maintenance of transport infrastructures; The objective is to transport passengers accounted for 86\% - 90\%, road freight accounted for 65\% - 70\% (Agarwal, 2008).

Vietnam has an ITS Application Roadmap, issued by the Ministry of Transport, divided into 3 stages: the period from 2015 to 2015 , the period from 2015 to 2020 and the period from 2020 to 2030. The objective of this roadmap is: Nationally standardized ITS; Planning and constructing traffic control and control centers in 3 regions of North, Central and South; and build complete applications, ITS subsystems (Liao \& Wang, 2018).

A number of ITS projects have been implemented in big cities like Hanoi, Ho Chi Minh City, and Da Nang: In Hanoi, the Traffic Control Center was officially put into operation in 2000 with the equipment system of SAGEM controlling traffic lights sponsored by the French Government. It can be said that this is the first application of ITS technology in urban areas in Vietnam. Up to now, this center has been upgraded many times and is still operating effectively, contributing to the supervision and administration of traffic throughout the city. The pilot project of constructing the management model of Thang Long Boulevard with the formation of the Hanoi Highway Management Center. This center manages traffic safety, access to traffic accident handling and preventive measures; information system management; perform warranty, repair ... The center will apply modern information technologies in management such as counting and classifying automatic vehicles; camera surveillance systems; electronic bulletin board systems; control of overloaded and oversized vehicles, etc. The REMON project is implemented in Hanoi with the aim of monitoring and determining traffic volume online and creating traffic data sources for both short-term and long-term periods ( $\mathrm{H}$. T. Pham \& Lee, 2019). This project uses supervised vehicles (speed and direction of movement), location via GPS system to collect data and reflect traffic situation, detect congestion locations, thereby providing information to users. Information collected to serve traffic management and administration, planning evaluation and solutions for traffic organization and control, planning development, long-term development strategy to address transportation issues. (Gohar, Muzammal, \& Ur Rahman, 2018)

In Da Nang, the Da Nang Department of Transport cooperated with IBM to develop an ITS program for the whole city. Operating Center traffic lights and public transport Da Nang City installs a traffic surveillance camera system, supports supervision, administration and helps the police force to supervise the violations and proceed to implement "cold sanctions". The project to build and upgrade the traffic signal system and control of Da Nang City was carried out from 2004 to 2012 from Spain's ODA, conducting coordination control of intersections on some routes in the form of "green wave" (Schlingensiepen et al., 2016).

In Ho Chi Minh City, a traffic control center has also been built. A traffic monitoring camera system is installed. The city is implementing the program "Application of Science and Technology to reduce traffic congestion for the period 20132015 with a vision to 2020 " in order to "Research, test and put into use technological solutions for ITS to improve the efficiency of exploitation and development of existing transport infrastructure system in the city, contribute to resolving traffic congestion" (Kans, Galar, \& Thaduri, 2016).

In the field of public transport, the application of ITS has also started to be researched and implemented through the electronic signage system that provides information about vehicle distance to a stop for passengers (installed at bus stops). Looking ahead, in Hanoi and HCMC. In Ho Chi Minh City, a number of urban railways will be put into operation and expected to use the smart payment card system according to Japanese technology standards to serve the purchase of tickets. In addition, Japan is also helping the two cities to implement a pilot "Public Transport Improvement" project using smart cards for buses. The use of a traffic VOV radio system in collecting, providing information and regulating traffic has brought many positive effects in Hanoi capital, Ho Chi Minh City, Hai Van road tunnel. This is a simple but effective method, contributing to limiting traffic congestion in urban areas and key areas. 
Thus, it can be seen that the application of ITS in Vietnam has many favorable conditions related to infrastructure systems, policies, strategies and priorities for development investment. However, this process also has many issues that need to be overcome, requiring Vietnam to continue efforts and strengthen cooperation and exchange with countries around the world to complete and accelerate the process of ITS application.

\section{Comment}

Through research, analysis, evaluation, we can identify the difficulties and challenges for the application of ITS in urban planning in general and transportation planning in particular as follows:

Lack of legal framework for ITS integration in transport planning in particular and urban planning in general. There are no standards, ITS standards, the implementation of construction is still according to foreign standards, so it is inconsistent and may not be suitable for Vietnamese conditions (Deka, Khan, Chowdhury, \& Ayres, 2018).

The lack of a master plan makes the deployment work specific lack of science (not knowing where to start, what application to develop first, handling cargo or passengers ...), overlapping orientations, difficulties in management and investment.

There are many studies on ITS, but these studies are fragmented, independent and lack coordination leading to low research effectiveness. Moreover, there is no unified organization in charge of ITS research, application, and development in Vietnam. This greatly affects the orientation, strategy, and management of ITS research and implementation.

Cities deploy applications according to the needs of each city and according to different foreign standards and regulations, synchronization in the whole country is very difficult and expensive. Moreover, it is difficult to be a model for application in other cities.

High-quality human resources are inadequate, and experience in implementing many ITS services are limited (traffic management is often the work of traffic police, who are not qualified as transport engineers. Police officers often focus their efforts only on trying to operate and enforce traffic with little attention to traffic management planning and design. Software or applications and development plans are purchased and transferred from countries that do not have Vietnamese designs, so they are not really suitable for our country's conditions.

\section{PLANNING INTEGRATION}

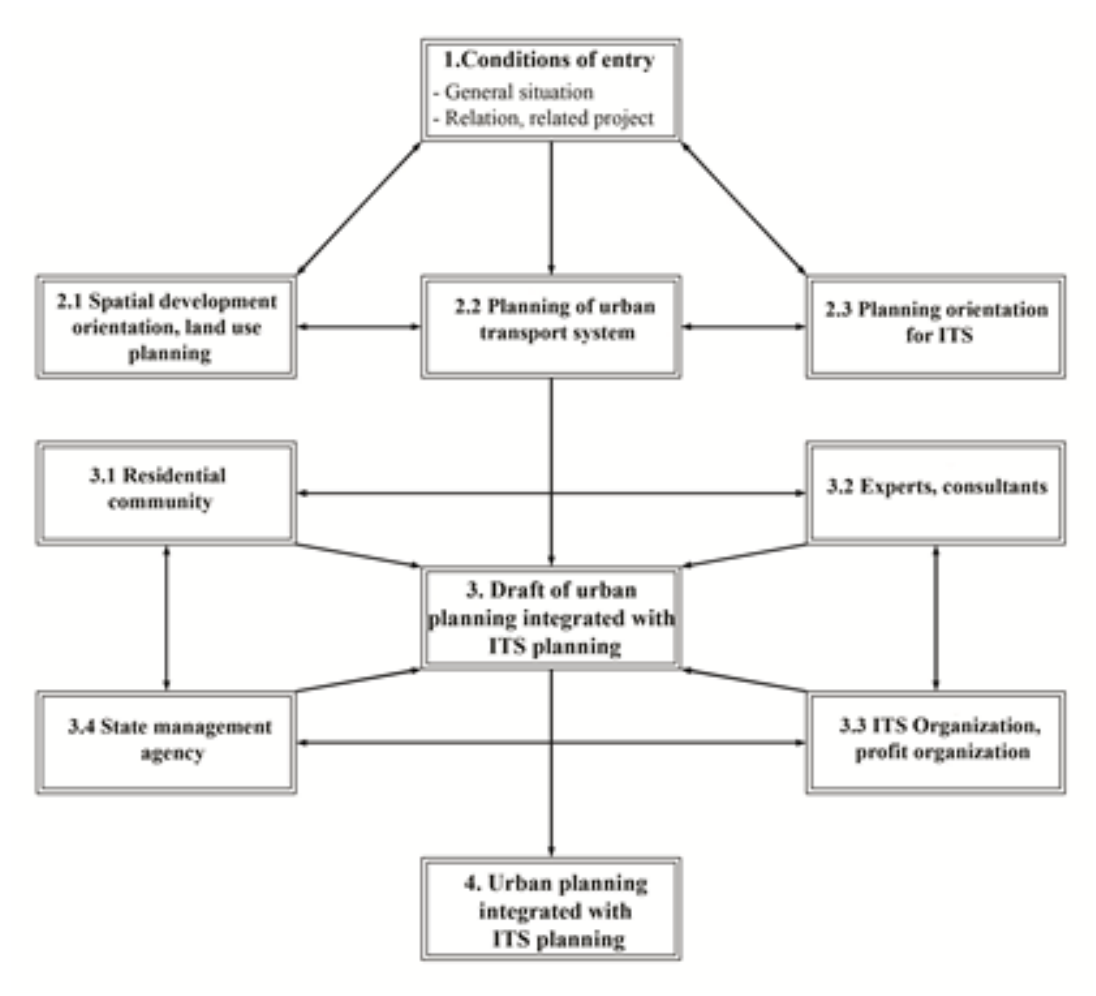

Figure 2: ITS planning integration process in Urban planning (Faga, 2019)

In order to develop synchronously and unify the urban transport system in particular and the urban area in general, ITS integration needs to start investing in the planning stage. This study proposes the integrated content of ITS planning in 4step urban planning as shown in Figure 2. 


\section{Conditions of entry}

Analyze and assess factors of natural conditions, socio-economic conditions, science and technology, current status of landscape architecture and technical infrastructure, current land use status, the relevant plans and projects have been approved ... as a basis for spatial development and appropriate urban land use (Muhammad et al., 2018).

For the transport system: it is necessary to assess the current situation and decentralize routes; analysis of directions, main traffic volume; congestion points, time of congestion, causes of congestion; types of transport and coordination between types of transport; traffic construction system; analyze and evaluate the current status of the ITS system; related transport development orientations ... as a basis for proposing solutions in the planning section (Pedrielli, Chew, Lee, \& White, 2016).

\section{Research, integrated recommendations}

After analyzing and assessing input conditions to propose basic ideas about spatial development orientation and land use structure of the urban area (step 2.1); conduct traffic analysis, evaluation and calculation to propose the connection network (traffic, cross-section structure, sub-main network, traffic works ...) according to the traditional method without ITS integrated (step 2.2). After the results in step 2.2 are conducted, ITS applications will be integrated into the planned transportation system (management center, application software, management services ... and these applications are suitable to local socio-economic and scientific and technical conditions and specified in the system of standards and ITS standards).

For these ITS applications, reverse review the transport network proposal in step 2.2: when all the needs of the user are fully provided, strictly managed, effectively supervised and operated, ensuring fast and convenient connection, whether or not it is necessary to readjust the specifications of the road network? Usually, when there is no management, regulation, distribution of the ITS system, the routes to achieve a stable flow level, being able to freely choose the speed, the crosssection must be very large; or transshipment centers, logistics warehouses are also significant scale ... Therefore, when it is applied, it is possible to reduce the traffic area substantially while achieving the desired transport orientation and land-use efficiency. After integrating ITS in step 2.3 into the transport network proposal in step 2.2; go back to step 2.1 to adjust the land use structure and the orientation of spatial development in a rational, efficient, uniform and sustainable manner (Makino et al., 2018).

\section{Consultation, approval, and issuance}

Summarizing the results of steps 1 and 2, preparing a draft Urban Planning integrated with ITS planning. After conducting the workshop to collect public comments of relevant parties such as community; experts, consultants; ITS organization, profit organizations; competent state management agencies; synthesize and unify the development of urban planning integrated with ITS planning (step 3). After completing step 3, competent state management agencies shall issue decisions to approve, promulgate and publicize planning as a basis for management and implementation of subsequent planning steps and projects.

\section{CONCLUSION}

Transport plays a central role in the process of urban development, especially in the process of forming urban spatial structure, form urban functional areas as well as the level of development of urban land use activities. The urban planning system in our country is still influenced by the functional administrative management model, resulting in 4 different master plans in the city and especially the research content and the role of infrastructure and capacity of public transport always play a central role in all 4 plans. The interplay between the plans makes the scientific, practical and topical aspects of the planning options seriously affected.

\section{THE IMPLICATIONS OF THIS STUDY AND FINDINGS}

Smart cities or any type of capital city are geared towards sustainable development, longevity and the human factor. In all these urban forms, traffic is always a top priority as a lifeline connecting urban, urban with urban and national with national. When science and technology have developed rapidly, smart transportation is an indispensable development towards a smart city. The first and foremost thing starts with the planning work. For Vietnam today, as one of the latecomers in ITS research as well as smart cities, it is necessary to promulgate regulations on smart transport planning and smart cities; ITS standards; establishing a unified management agency; formulating plannings and development strategies for ITS and national smart cities before piloting construction in urban centers to ensure consistency and sustainability.

\section{ACKNOWLEDGMENT}

I would like to thank the Academy of Politics Region II for supporting the author in compiling the data for this study.

\section{REFERENCES}

1. Agarwal, R. (2008). Public transportation and customer satisfaction: the case of Indian railways. Global Business Review, 9(2), 257-272. https://doi.org/10.1177/097215090800900206

2. Buszynski, L., \& Roberts, C. B. (2014). The South China Sea maritime dispute: Political, legal and regional 
perspectives. The South China Sea Maritime Dispute: Political, Legal and Regional Perspectives. https://doi.org/10.4324/9781315858029

3. Chen, C., Tabssum, N., \& Nguyen, H. P. (2019). Study on Ancient Chu Town Urban Green Space Evolution and Ecological and Environmental Benefits. Nature Environment and Pollution Technology, 18(5), 1733-1738.

4. Choi, Y., \& Mai, D. (2018). The sustainable role of the e-trust in the B2C e-commerce of Vietnam. Sustainability, 10(1), 291. https://doi.org/10.3390/su10010291

5. Deka, L., Khan, S. M., Chowdhury, M., \& Ayres, N. (2018). Transportation Cyber-Physical System and its importance for future mobility. Transportation Cyber-Physical Systems. Elsevier Inc. https://doi.org/10.1016/B978-0-12-814295-0.00001-0

6. Faga, B. (2019). Urban design. In The Routledge Handbook of International Planning Education. https://doi.org/10.4324/9781315661063-24

7. Gohar, M., Muzammal, M., \& Ur Rahman, A. (2018). SMART TSS: Defining transportation system behavior using big data analytics in smart cities. Sustainable Cities and Society, 41, 114-119. https://doi.org/10.1016/j.scs.2018.05.008

8. Hoang, A. T., Le, V. V., Pham, V. V., \& Tham, B. C. (2019). An investigation of deposit formation in the injector, spray characteristics, and performance of a diesel engine fueled with preheated vegetable oil and diesel fuel. Energy Sources, Part A: Recovery, Utilization, and Environmental Effects, 1-13. https://doi.org/10.1080/15567036.2019.1582731

9. Hoang, A. T., \& Pham, V. V. (2018). A review of fuels used for marine diesel engines. Journal of Mechanical Engineering Research \& Developments, 41(4), 22-32. https://doi.org/10.26480/jmerd.04.2018.22.32

10. Hoang, A. T., \& Pham, V. V. (2019). A study of emission characteristics, deposits, and lubrication oil degradation of a diesel engine running on preheated vegetable oil and diesel oil. Energy Sources, Part A: Recovery, Utilization, and Environmental Effects, 41(5), 611-625. https://doi.org/10.1080/15567036.2018.1520344

11. Jahn, C., Kersten, W., \& Ringle, C. M. (2018). Logistics 4.0 and sustainable supply chain management: innovative solutions for logistics and sustainable supply chain management in the context of industry 4.0. In Hamburg International Conference of Logistics (HICL) 2018. epubli.

12. Jiang, R., \& Wang, Y.-S. (2018). Modeling the ecosystem response to summer coastal upwelling in the northern South China Sea. Oceanologia, 60(1), 32-51. https://doi.org/10.1016/j.oceano.2017.05.004

13. Kans, M., Galar, D., \& Thaduri, A. (2016). Maintenance 4.0 in the railway transportation industry. In Proceedings of the 10th world congress on engineering asset management (WCEAM 2015) (pp. 317-331). Springer. https://doi.org/10.1007/978-3-319-27064-7_30

14. Li, L., Qu, X., Zhang, J., Wang, Y., \& Ran, B. (2019). Traffic speed prediction for intelligent transportation system based on a deep feature fusion model. Journal of Intelligent Transportation Systems, 23(6), 605-616. https://doi.org/10.1080/15472450.2019.1583965

15. Liao, D.-Y., \& Wang, X. (2018). Applications of Blockchain Technology to Logistics Management in Integrated Casinos and Entertainment. In Informatics (Vol. 5, p. 44). Multidisciplinary Digital Publishing Institute. https://doi.org/10.3390/informatics5040044

16. Lom, M., Pribyl, O., \& Svitek, M. (2016). Industry 4.0 as a part of smart cities. In 2016 Smart Cities Symposium Prague (SCSP) (pp. 1-6). IEEE. https://doi.org/10.1109/SCSP.2016.7501015

17. Makino, H., Tamada, K., Sakai, K., \& Kamijo, S. (2018). Solutions for urban traffic issues by ITS technologies. IATSS Research, 42(2), 49-60. https://doi.org/10.1016/j.iatssr.2018.05.003

18. Massard, G., Leuenberger, H., \& Dong, T. D. (2018). Standards requirements and a roadmap for developing ecoindustrial parks in Vietnam. Journal of Cleaner Production, 188, 80-91. https://doi.org/10.1016/j.jclepro.2018.03.137

19. Mihankhah, T., Delnavaz, M., \& Khaligh, N. G. (2016). Eco-friendly biodiesel production from olive oil waste using solar energy. Energy Sources, Part A: Recovery, Utilization, and Environmental Effects, 38(24), 36683672. https://doi.org/10.1080/15567036.2016.1167792

20. Muhammad, B., Kumar, A., Cianca, E., \& Lindgren, P. (2018). Improving Port Operations through the Application of Robotics and Automation within the Framework of Shipping 4.0. International Symposium on Wireless Personal Multimedia Communications, WPMC, 2018-Novem, 387-392. https://doi.org/10.1109/WPMC.2018.8712998

21. Nguyen, X. P. (2019). The bus transportation issue and people's satisfaction with public transport in Ho Chi Minh city. Journal of Mechanical Engineering Research and Developments. https://doi.org/10.26480/jmerd.01.2019.10.16

22. Nisar, T. M., \& Prabhakar, G. (2017). What factors determine e-satisfaction and consumer spending in ecommerce retailing? Journal of Retailing and Consumer Services. https://doi.org/10.1016/j.jretconser.2017.07.010

23. Pedrielli, G., Chew, E. P., Lee, L. H., \& White, C. (2016). Singapore: The future of logistic hubs. 50 Years of Transportation in Singapore: Achievements and Challenges, 348-402. https://doi.org/10.1142/9789814651608_0006

24. Pham, H. T., \& Lee, H. (2019). Developing a Green Route Model for Dry Port Selection in Vietnam. The Asian Journal of Shipping and Logistics, 35(2), 96-107. https://doi.org/10.1016/j.ajs1.2019.06.002 
25. Pham, V. T. (2019). Critical information for the Vietnamese economy aiming at a strategic breakthrough as approaching the industry 4.0. International Journal on Advanced Science, Engineering and Information Technology, 9(3), 1008-1016. https://doi.org/10.18517/ijaseit.9.3.8517

26. Phuong, N. H. (2019). What solutions should be applied to improve efficiency in the management of the port system in Ho Chi Minh City? International Journal of Innovation, Creativity and Change, 5(2), 1747-1769.

27. Raval, N., \& Gupta, A. K. (2015). Historic Developments, Current Technologies and Potential of Nanotechnology to Develop Next Generation Solar Cells with Improved Efficiency. International Journal of Renewable Energy Development, 4(2). https://doi.org/10.14710/ijred.4.2.77-93

28. Razmjoo, A., \& Davarpanah, A. (2019). Developing various hybrid energy systems for a residential application as an appropriate and reliable way to achieve Energy sustainability. Energy Sources, Part A: Recovery, Utilization, and Environmental Effects, 41(10), 1180-1193. https://doi.org/10.1080/15567036.2018.1544996

29. Schlingensiepen, J., Nemtanu, F., Mehmood, R., \& McCluskey, L. (2016). Autonomic transport management systems - an enabler for smart cities, personalized medicine, participation and industry grid/industry 4.0. In Intelligent transportation systems-problems and perspectives (pp. 3-35). Springer. https://doi.org/10.1007/978-3319-19150-8_1

30. Smajgl, A., Toan, T. Q., Nhan, D. K., Ward, J., Trung, N. H., Tri, L. Q., .. Vu, P. T. (2015). Responding to rising sea levels in the Mekong Delta. Nature Climate Change. https://doi.org/10.1038/nclimate2469

31. Tokody, D., Mezei, I. J., \& Schuster, G. (2017). An overview of autonomous intelligent vehicle systems. InVehicle and Automotive Engineering (pp. 287-307). Springer. https://doi.org/10.1007/978-3-319-51189-4_27

32. Walker, T. R., Adebambo, O., Del Aguila Feijoo, M. C., Elhaimer, E., Hossain, T., Edwards, S. J., ... Zomorodi, S. (2019). Environmental Effects of Marine Transportation. World Seas: an Environmental Evaluation (Second Edi). Elsevier Ltd. https://doi.org/10.1016/B978-0-12-805052-1.00030-9

33. Wang, C., Lu, W., Xi, C., \& Nguyen, X. P. (2019). Research on Green Building Energy Management Based on BIM and FM. Nature Environment and Pollution Technology, 18(5), 1641-1646.

34. Xiong, G., Zhu, F., Liu, X., Dong, X., Huang, W., Chen, S., \& Zhao, K. (2015). Cyber-physical-social system in intelligent transportation. IEEE/CAA Journal of Automatica Sinica, 2(3), $320-333$. https://doi.org/10.1109/JAS.2015.7152667

35. Xu, Z., Zhai, S., \& Nguyen, X. P. (2019). Research on green transition development of energy enterprises taking the mining industry as an example. Nature Environment and Pollution Technology, 18(5), 1521-1526.

36. Yu, W., \& Zhao, F. (2019). Prediction of critical properties of biodiesel fuels from FAMEs compositions using intelligent genetic algorithm-based back propagation neural network. Energy Sources, Part A: Recovery, Utilization, and Environmental Effects, 1-14. https://doi.org/10.1080/15567036.2019.1641575

37. Zhang, L., Li, C., \& Phuong, N. H. (2019). Economic Development of Biomass Energy Industry in Heilongjiang Province Based on the Analytic Hierarchy Process. Nature Environment and Pollution Technology, 18(5), 14871493.

38. Zhang, T., Zhou, W., Meng, F., \& Li, Z. (2019). Efficiency Analysis and Improvement of an Intelligent Transportation System for the Application in Greenhouse. Electronics, 8(9), 946. https://doi.org/10.3390/electronics8090946 